\title{
Mass Spectrometric Studies of Sulfur Compounds: The Alpha and Beta Substituted Naphthylthiaalkanes
}

\author{
Norman G. Foster*, Robert W. Higgins*† and Mynard C. Hamming**
}

(Received September 1, 1979)

\begin{abstract}
The mass spectra of fifteen members of the alpha and beta substituted naphthylthiaalkanes with a molecular weight range of 202 to 300 are reported. The data are used to illustrate the process of correlation and delineation of fragmentation routes in a class of compounds to benefit mass spectroscopists. Spectra from low, medium, and high resolution instruments are employed, showing the necessity and usefulness of multiple approaches in obtaining a complete understanding of the pathways involved. Application of low ionization voltage, metastable ion data, doubly charged ions, and high resolution mass spectrometry is described to arrive at an outline of the major fragmentation routes in a given class of compounds. For unknown compounds in their class, the analyst can readily make an identification from the predicted mass spectrum by utilizing this information.
\end{abstract}

\section{Introduction}

This report covers a portion of an extensive program to determine the reference mass spectra of a number of classes of organosulfur compounds. The presence of large quantitities of sulfur containing compounds in much of the world's fossil fuel supplies leads to problems for both the processing and refining of such materials. Undesirable products from the incomplete combustion of sulfur containing fuels are also a problem. Identification of these classes of compounds requires reference spectra, whether mass, nuclear magnetic resonance, or infrared. In lieu of the availability of a plethora of such spectra, the mass spectroscopist can utilize the class approach to study fragmentation mechanisms for previously unreported compounds. From this information, predictions of the behavior of the entire class can be made.

*Texas Woman's University, Denton, Texas 76204.

**Research and Development Department, Conoco Inc., Ponca City, Oklahoma 74601.

†Deceased

Person to contact regarding this manuscript: Mynard C. Hamming. 
Fifteen members of the alpha and betanaphthylthiaalkanes are studied and discussed in this work. Mass spectra of some thienylthiaalkanes have been reported $^{1,2)}$, as have the alkylthiaalkanes ${ }^{3,4,5,8)}$. Anumber of other classes of sulfur compounds have been studied and most of these can be found in the listing of spectra in Hamming and Foster's text ${ }^{7}$.

The mass spctroscopist prefers to have a number of isomers of the class to be studied, extending to alkyl chain lengths of at least 8 carbon atoms and including some branched chain compounds for each species of compounds to be studied. In the case of multisubstitutions upon ring system compounds, this might require many individual isomers, beyond the possibility of synthesis. This further justifies correlation studies to expound fragmentation mechanisms which can be applied in similar systems. The studies of Meyerson and his coworkers ${ }^{8,9,10)}$ on the alkylbenzenes are examples of how fragmentation principles have been applied to other aromatic systems at a later time.

Kinney and $\mathrm{Cook}^{11}$ and Cook and Foster ${ }^{2)}$ showed similar correlations for the alkylthiophenes and indicated important differences in fragmentation behavior due to the presence of the sulfur atom in the ion moieties. Frequently the tertiary butyl, isopropyl, and sometimes the methyl deriv. atives of such compounds give spectra not in accord with the mechanisms proposed for the class. The differences were usually typical of that type of alkyl group and are observed wherever the general structural conditions permitted. Budzikiewicz, Djerassi and Williams ${ }^{12)}$ have summarized several skeletal rearrangements that have been observed for aromatic thioethers. In mass spectra of alkyl ethers of thiophenols, $\alpha$ fission accounts for the intense peaks at $m / z$ 123. This fragmentation can be compared to the formation of the $m / z 173$ ion from the naphthylthiaalkanes discussed here. With this background available, the mass spectroscopist has an advantage in utilizing the class approach to fragmentation mechanisms. Any spurious production of a given ion can be detected early, and if the purity of the substance becomes a question, this too can be resolved by considering the "fit" of that particular compound into the general fragmentation scheme. As an instructive case, the mass spectra of the alpha and beta-naphthylthiaalkanes are presented.

\section{Experimental}

The compounds studied were prepared by Dr. Higgins and his students by standard methods of organic syntheses. The compounds were vacuum distilled at low pressures immediately following their synthesis and stored under nitrogen in brown bottles. These compounds were examined without further purification because of their high molecular weight and thermal sensitivity to high temperature chromatography.

The positional substitution of the thiaalkyl groups on the naphthalene ring was verified from an infrared spectrum obtained on a Perkin-Elmer Model 225 infrared spectrophotometer. Three mass spectrometers were employed: a Consolidated Electrodynamics Corporation (CEC) Model 103 was used to examine the materials in a low resolution situation. A CEC-104 
Mass Spectrometcric Studies of Sulfur Compounds :

Table 1. Partial mass spectra of alpha and beta-naphthylthiaalkanes, $\%$ of total ion intensity (CEC-103 data).

The alpha substituted compounds

\begin{tabular}{|c|c|c|c|c|c|c|c|c|c|c|c|c|c|}
\hline \multirow{2}{*}{$\begin{array}{l}\text { Alkyl } \\
\text { Group }\end{array}$} & \multirow{2}{*}{$\begin{array}{l}\text { Purity } \\
\text { Mole \% }\end{array}$} & \multicolumn{2}{|c|}{ Molecular Ion } & \multirow{2}{*}{$\begin{array}{c}\beta+H \\
160\end{array}$} & \multirow{2}{*}{$\begin{array}{c}\beta \\
159\end{array}$} & \multirow{2}{*}{$\begin{array}{l}\beta+2 H \\
161^{*}\end{array}$} & \multirow{2}{*}{$\begin{array}{c}\alpha+\mathrm{H} \\
128\end{array}$} & \multirow{2}{*}{$\begin{array}{c}\alpha \\
127\end{array}$} & \multirow{2}{*}{$\begin{array}{c}\alpha+2 \mathrm{H} \\
129\end{array}$} & \multicolumn{3}{|c|}{$\gamma$ Other Ions } & \multirow{2}{*}{$\begin{array}{l}\text { Sum** } \\
\text { Alkyls }\end{array}$} \\
\hline & & $m / z$ & Int. & & & & & & & 173 & 115 & 45 & \\
\hline $\mathrm{nC}_{4}$ & 99.8 & 216 & 12.4 & 19.9 & 2.8 & 0.16 & 2.7 & 1.7 & 1.1 & 2.1 & 9.0 & 4.5 & 11.2 \\
\hline $\mathrm{nC}_{5}$ & 98.8 & 230 & 11.5 & 18. 0 & 2.7 & 0.14 & 1.9 & 1.3 & 0.8 & 1.8 & 6.5 & 2.5 & 14.4 \\
\hline $\mathrm{nC}_{6}$ & 96.9 & 244 & 12.4 & 18.9 & 2.9 & 0.18 & 2.2 & 1.5 & 1.0 & 2.0 & 7.4 & 2.0 & 15.5 \\
\hline $\mathrm{nC}_{7}$ & 99.8 & 258 & 13.6 & 18.2 & 2.9 & 0.19 & 2.1 & 1.5 & 1.0 & 2.1 & 6.8 & 1.9 & 15.0 \\
\hline $\mathrm{nC}_{8}$ & 97.0 & 272 & 14.2 & 16.7 & 2.5 & 0.37 & 2.1 & 1.4 & 1.3 & 2.0 & 6.1 & 2.5 & 14.1 \\
\hline $\mathrm{nC}_{10}$ & 99.9 & 300 & 15.6 & 14.3 & 2.8 & 0.25 & 1.6 & 1.1 & 0.8 & 2.0 & 4.8 & 1.6 & 16.0 \\
\hline $\mathrm{iC}_{4}$ & 99.2 & 216 & 9.6 & 20.8 & 2.3 & 0.10 & 2.3 & 1.8 & 1.4 & 2.8 & 7.8 & 3.0 & 13.0 \\
\hline $\mathrm{iC}_{5}$ & 98.4 & 230 & 10.6 & 21.5 & 2.6 & 0.16 & 2.5 & 1.8 & 1.3 & 3.0 & 7.5 & 2.8 & 12.4 \\
\hline \multicolumn{14}{|c|}{ The beta substituted compounds } \\
\hline $\mathrm{nC}_{3}$ & 98.2 & 202 & 12.3 & 16.1 & 2.4 & 0.10 & 3.1 & 2.2 & 1.7 & 4.4 & 9.5 & 3.5 & 7.6 \\
\hline $\mathrm{nC}_{4}$ & 98.9 & 216 & 12.8 & 17.1 & 2.5 & 0.26 & 2.8 & 1.9 & 1. 4 & 3.3 & 8.6 & 3.1 & 11.4 \\
\hline $\mathrm{nC}_{6}$ & 95.4 & 244 & 12.0 & 19.8 & 3.4 & 0.0 & 2.5 & 1.7 & 1.5 & 2.6 & 7.4 & 2.9 & 12.8 \\
\hline $\mathrm{nC}_{8}$ & 97.9 & 272 & 14.8 & 17.1 & 2.1 & 0.22 & 2.0 & 1.3 & 1.0 & 2.8 & 6.5 & 1.8 & 15.2 \\
\hline $\mathrm{nC}_{10}$ & 99.4 & 300 & 13.4 & 16.9 & 2.0 & 0.39 & 1.7 & 1.0 & 1.0 & 2.7 & 4.2 & 1.9 & 13.6 \\
\hline $\mathrm{iC}_{5}$ & 98.5 & 230 & 10.9 & 22.2 & 3.3 & 0.0 & 2.3 & 1.5 & 1.0 & 1.8 & 8.8 & 2.0 & 13.0 \\
\hline cyclo $\mathrm{C}_{6}$ & 99.7 & 242 & 7.9 & 28.3 & 2.4 & 0.03 & 2.1 & 1.1 & 0.3 & 0.2 & 8. 4 & 0.8 & 5.3 \\
\hline
\end{tabular}

*Excess above isotopic contributions from $m / z 159$ and 160 peaks.

**Sum Alkyls $=m / z 41,43,55,57,69,71,83,85,97$, and 99, etc.

instrument was used to determine the Low Voltage Mass Spectrometry (LVMS) purities, for examination at low ionization voltages, and for intermediate resolution work. A CEC-110 instrument was used to obtain high resolution data and, in some instances, metastable ion information. These instruments were operated at nominal standard conditions for each type of spectrum desired. Table 1 contains a listing of these compounds, their approximate purities, and partial mass spectral data. Complete low resolution mass spectral data is to be found in the American Petroleum Institute Research Project 44 (API-RP-44) files as Serial Numbers: 433-m to $447-\mathrm{m}^{13)}$.

\section{Results and Discussion}

\section{The Alpha Naphthylthiaalkanes}

A strong molecular ion intensity is noted for all the compounds, with a slight decrease in intesity for the two isoalkyl derivatives examined. The ion of largest intensity in each spectrum is a rearrangement ion at $m / z 160$ coming from cleavage beta from the naphthyl ring and alpha to the sulfur atom. A hydrogen atom is rearranged from somewhere on the alkyl chain. Earlier work with deuterated alkylthiophenes shows a similar rearrangement which is partially a McLafferty-type rearrangement and partially a random process ${ }^{14}$. Evidence from thienyl sulfides ${ }^{1,2)}$ and the benzo (b) thienyl sulfides ${ }^{14)}$ also supports 
this type of behavior with only a part of the hydrogen transfer coming through a McLafferty-type rearrangement. Considertion of the doube McLafferty rearrangement in which two hydrogens move indi. cates less than 2 percent excess above the expected isotopic contribution on the $\mathrm{m} / \mathrm{z}$ 161 ion. Therefore, this is insignificant and unimportant in the case of these types of sulfur compounds. The ion at $m / z 159$, formed either by direct beta cleavage or possibly by the loss of a neutral hydrogen atom from the rearrangement peak at 160 , is only from 10-15 percent of the intensity of the 160 ion. Direct cleavage at the position will produce the $m / z 173$ ion and of less intensity than the 159 ion in all cases for the n-alkyl compounds. The isoalkyl compounds have an $m / z 173$ greater than 159 , apparently due to the chain branching.

Additional peaks at $m / z 127,128$, and 129 are shown. These may be formed by direct alpha cleavage to the ring, alpha with one hydyogen rearrangement, and alpha with two hydrogens rearranging. The $m / z 128$ ion is of somewhat greater intensity than the other two ions in each case. This is unlike the naphthalenes, or alkylbenzenes, but does resemble alpha cleavage in the alkylthiophenes. As in naphthalene spectra, an $m / z \quad 115$ ion is detected which is $\mathrm{C}_{9} \mathrm{H}_{7}{ }^{+}$, and which is possibly a daughter of the above ions. It is surprisingly large and may originate direct ly from the $m / z 160$ rearrangement ion. If so, the ion at $m / z 45$ would represent the same process except for charge competition among the sulfur containing moiety and the 115 ion. In this case, the neutral ejected would be the mass 115 , whereas the pro- duction of the 115 ion would require a neutral mass 45 ejected. The amount of 115 ion decreases with increasing chain length, and the 45, while also decreasing, appears to be increasing in relation to the 115.

\section{The Beta-Naphthylthiaalkanes}

The strong parent ion intensity is expected, as is the rearrangement ion at $m / z$ 160. The intensity of the molecular ion plus the rearrangement ion accounts for about 30 percent of the total ionization for each compound, regardless of whether alpha or beta. An important exception is the cyclohexyl substituted compound with a smaller molecular ion and considerably larger intensity rearrangement ion. This should be expected in light of the chain branching adjacent to the sulfur atom. A comparison of the apparently direct beta and gamma cleavages at $m / z \quad 159$ and 173 lead one to the observation that $m / z 159$ is less than 173 in intensity for the $n$ alkyl derivatives, whereas the reverse was true for the alpha substituted compounds. By the same token, for the isoalkly compounds, the ratio is reversed, leading to a very unusual situation for setting up correlations. It also raises interesting questions of mechanisms and spatial conformation problems which can not be answered from these data alone.

Similar intensities for the $m / z$ 127129 ions are observed for the beta substituted compounds as in the case of the alpha compounds. This suggests that these ions are formed by the same mechanism regardless of the positional substitution on the naphthalene ring. For the ions at $\mathrm{m} / \boldsymbol{z}$ 
115 and 45 , the only apparent difference is a slight increase in the intensity of both ions at a given carbon number. The cyclohexyl compound is again an exception giving an $m / z 45$ intensity far less than might be expected. The implication is that for the n-alkyl componnds, the $m / z 45$ ion may have its origin from a fragment containing the sulfur atom and the adjacent primary carbon atom of the alkyl chain. The presence of the branching requires considerably different fragmentation, which obviously does not lead to the 45 ion. That several mechanisms may be participating is shown by an increase of the 115 ion due to the charge competition in alpha cleavage to produce a 115 ion due to the presence of $\mathrm{S}-\mathrm{R}$ where $\mathrm{R}$ is cyclohexyl(or 83 plus $32=115$ ). This will be considered further at a later point in this work.

The last column in Table 1 presents a sum of the alkyl ions appearing in these spectra. It is to be noted that shorter chain substitution produces fewer alkyl fragments, but once the chain length gets to $8-10$ carbon atoms, a leveling off in intensities occurs. The n-propyl beta subsituted compound shows the fewest alkyl fragments and at the same time the largest ion at $m / z$ 115. The lowest alkly intensity occurs for the cyclohexyl isomer, once again indicating a preferred loss of a neutral cyclohexene moiety with the transfer of a hydrogen atom to the charged species. The alkyl ion intensities do not dominate the spectra as they do in the thienyl-3and 4-thiaalkanes ${ }^{1)}$. The alkyl ions are of litttle diagnostic value except as to indicate the chain length, chain branching, and when used with low ionizing voltage data.

\section{Low ionization voltage data}

Low ionization voltage information can often assist the mass spectroscopist, not only in determining possible fragmentation mechanisms, but also may be diagnostic for the analysis of specific isomers, differentiation of substitution, etc. In Figure 1, data are presented for four selected compounds which illustrate much of the behavior for this series of compounds. For the beta-n-propyl compound, the $m / z 43$ ion appears to come as a first fragment from the molcular ion, but then levels off in intensity rapidly as the ionizing voltage is increased. Not shown is the $m / z 41$ ion which appears as a daughter ion from it. The $m / z 45$ ion appears at the same time as the $m / z 128$ and 76 ions. Neither the 45 or 76 are shown because they are only important ions in the short chain molecules. However, $76\left(\mathrm{SC}_{3} \mathrm{H}_{6}\right)$ always appears concurrently with the 128 , suggesting that a hydrogen atom can move from either side of the sulfur atom to form a charged moiety. The intensity of the 128 ion is much larger in all compounds examined. One must conclude that the alpha cleavage with a hydrogen transfer is an energetically favored process, but which at higher energies gives way to the production of the $m / z 160$, or base peak ion. Also not shown is the fact that the 116 ion appears just ahead of the 115 ion moiety, and well after the 45 ion, thus, at least as a low voltage process, destroying the concept of the mechanisms proposed earlier for the 45 and 115 ions. Thes events are carried forth in all of the other compounds examined. The gamma 


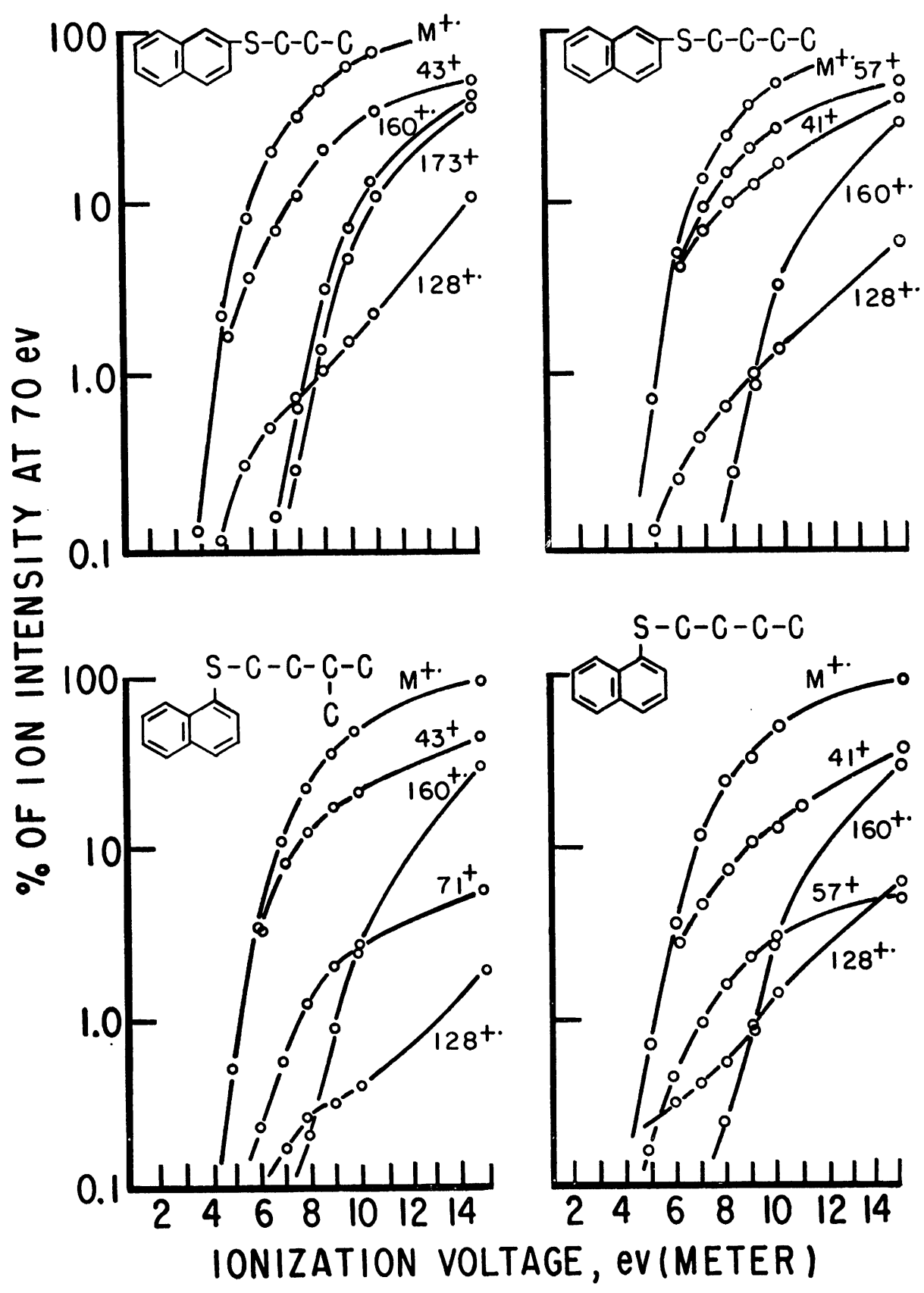

Fig. 1. Low ionization voltage data of some alpha and beta-Naphthylthiaalkanes. 
cleavage, or $m / z 173$ ions, appears after the 160 rearrangement and parallels it in growth throughout.

The beta n-butyl compound is similar except that $m / z 57$ is the first alkyl ion to appear, 43 is negligible, and $m / z 41$ becomes more prominent. The 173 ion (not shown) is less intense and does not increase as rapidly at low voltages as the same ion did in the propyl compound.

The beta-3-methlbutyl isomer (not shown) is much the same as the n-butyl compound except that $m / z 71$ is the principal alkyl ion, closely followed by the $m / z 43$ formed at the point of branching on the chain. In all three of these compounds, the alkyl ion appearing is first accompanied by the even ions at $m / z 42$, 56 , and 70 , respectively. This should assist the analyst.

For the beta-cyclohexyl compound (not shown), the $m / z 83$ ion is the first alkyl ion to appear, but practically at the same time, very minor peaks of $m / z 67,43,42$, and a modest intensity 41 ion appear. These could be expected from the breakup of the cyclohexyl fragment. The $\mathrm{M}^{++}$ion and the 160 ion appear just about the some as the other beta compounds.

The alpha n-butyl compound is presented as a comparison with the beta compound. Although most of the behavior is identical, one important difference exists. The $m / z 41$ ion is produced in much greater intensity than the 57 ion from the full alkyl chain. This suggests that the alpha compounds tend to fragment off parts of the chain easier than the beta compounds. Certainly the distribution of energy to the butyl fragment is different for the two isomers. Also showing this same behavior is the alpha-3-methylbutyl compound which produces considerably more $m / z 43$ ion than 71. Also examined were the alphaisobutyl and alpha-n-pentyl compounds. For the n-pentyl compound, the curve for the 71 ion was only slightly above that of the 43 ion. This confirms a different energy distribution within the alkyl chains in the case of the alpha substituted compounds. Other ions in the alpha spectra, i. e., 128, 76. etc, were much the same as in the beta spectra.

\section{Metastable ion data}

Metastable ion data was obtained from the high resolution instrument (CEC-110). Only seven of the compounds were examined using the CEC-110 with high resolution. A listing of the metastable ions observed is given in Table 2. A calculated value for the process is also included. It was possible to observe a metastable ion for the process producing the $m / z 160$ ion from the molecular ion for each compound. It must be remembered that some of the metastables observed could be for one or more processes. For example, a metastable ion shows from $m / z 114.1$ to 114.3 in 7 spectra. This could be from the process of $m / z 174$ losing a neutral HS fragment and producing the $m / z 141$ ion as well as for the loss of a hydrogen from 116 to give the 115 ion. The latter process appears more likely and hence is listed. Two things are evident from the data: (1) Generalized pathways of fragmentation can be verified, and (2) most of the fragments leaving are either small pieces, typical of aromatic fragmentation processes, or the loss of a 
N. G. Foster and R. W. Higgins, M. C. Hamming

Table 2. Selected metastable peaks observed in some naphthylthiaalkanes.

\begin{tabular}{|c|c|c|}
\hline $\begin{array}{l}\text { m* } \\
\text { Peak }\end{array}$ & $\begin{array}{l}\text { Number of Compounds } \\
\text { Observed in }\end{array}$ & Most Probable Transition \\
\hline $111.3-.4$ & 2 & $\mathrm{M}\left(230^{+}\right) \longrightarrow 160^{+}+\mathrm{R}-\mathrm{CH}=\mathrm{CH}_{2}{ }^{\circ}$ \\
\hline 105.8 & 1 & $\mathrm{M}\left(242^{+}\right) \longrightarrow 160^{+}+\mathrm{R}-\mathrm{CH}=\mathrm{CH}_{2}{ }^{\circ}$ \\
\hline 105.2 & 1 & $\mathrm{M}\left(244^{++}\right) \longrightarrow 160^{+\cdot}+\mathrm{R}-\mathrm{CH}=\mathrm{CH}_{2}{ }^{\circ}$ \\
\hline $93.8-94.2$ & 2 & $\mathrm{M}\left(272^{+}\right) \longrightarrow 160^{+\cdot}+\mathrm{R}-\mathrm{CH}=\mathrm{CH}_{2}^{\circ}$ \\
\hline 85.3 & 1 & $\mathrm{M}\left(300^{+*}\right) \longrightarrow 160^{+\cdot}+\mathrm{R}-\mathrm{CH}=\mathrm{CH}_{2}^{\circ}$ \\
\hline $81.1-.2$ & 1 & $\mathrm{M}\left(202^{+}\right) \longrightarrow 128^{+\cdot}+\mathrm{R}-\mathrm{CH}=\mathrm{CH}-\mathrm{SH}^{\circ}$ \\
\hline $70.9-71.3$ & 2 & $\mathrm{M}\left(230^{+}\right) \longrightarrow 128^{++}+\mathrm{R}-\mathrm{CH}=\mathrm{CH}-\mathrm{SH}^{\circ}$ \\
\hline 183. $2-.3$ & 5 & $187^{+} \quad \longrightarrow 185^{+}+\mathrm{H}_{2}^{\circ}$ \\
\hline 158.1 & 2 & $\longrightarrow 159^{+}+\mathrm{H}^{\circ}$ \\
\hline 125.2 & 6 & $\longrightarrow 147^{+}+\mathrm{C}_{2} \mathrm{H}_{2}^{\circ}$ \\
\hline 114.9 & 5 & $\longrightarrow 141^{+}+\mathrm{S}^{\circ}$ \\
\hline $114.1-.2$ & 6 & $\longrightarrow 115^{+}+\mathrm{H}^{\circ}$ \\
\hline 112.4 & 1 & $\longrightarrow 134^{++}+\mathrm{C}_{2} \mathrm{H}_{2}^{\circ}$ \\
\hline $102.3-.5$ & 5 & $\longrightarrow 128^{+}+\mathrm{S}^{\circ}$ \\
\hline $96.2-3$ & 4 & $\longrightarrow 129^{+}+\mathrm{CS}^{\circ}$ \\
\hline 93.8 & NONE & $\longrightarrow 115^{+}+\mathrm{C}_{2} \mathrm{H}_{2}^{\circ}$ \\
\hline $84.1-.2$ & 3 & $\longrightarrow 116^{+}+\mathrm{CS}^{\circ}$ \\
\hline $83 \cdot 2-.4$ & 4 & $\longrightarrow 115^{+}+\mathrm{CS}^{\circ}$ \\
\hline
\end{tabular}

long alkyl chain, either as a radical or as a neutral olefin in the case of the $m / z 160$ rearrangement ion. It is also noteworthy that the process for the direct production of the $m / z 128$ ion from the molecular species was only observed in the lower molecular weight compounds. This may account for the shape of the $m / z 128$ ion production curves in Figure 1 for the low ionization data. Since the 128 ion appears before the 160 ion in every case, one can conclude that both processes are taking place albeit with different appearance potentials.

\section{Doubly charged ions}

Table 3 contains a listing of doubly charged ions observed in all of the spectra.

Table 3. Doubly charged ions observed.

\begin{tabular}{rll}
\hline $\mathrm{m} / z$ & $2+$ ion & \multicolumn{1}{c}{ Comment } \\
\hline 57.5 & $115^{2+}$ & Typical in naphthalenes \\
63.5 & 127 & Atypical in naphthalenes \\
64.5 & 129 & Atypical in naphthalenes \\
73.5 & 147 & (benzothiapyrillrum) \\
79.5 & 159 & 159 disappears rapidly below $15 \mathrm{eV}$. \\
85.5 & 171 & \\
86.5 & 173 & Possibly from $\mathrm{M}^{2+} \longrightarrow 173^{2+}$ then $\longrightarrow 171^{+}$ \\
87.5 & 175 & Possibly isotope from $173^{2+}$ ion \\
92.5 & 185 & Probably from $187^{2+} \longrightarrow 185^{2+}+\mathrm{H}_{2}^{\circ}$ \\
93.5 & 187 & $(\mathrm{M}-15)^{2+}$, a high energy process \\
101.5 & $203^{2+}$ & In $\beta-\mathrm{nC}_{3}=(\mathrm{M}+1)^{2+}$ isotope peak \\
\hline
\end{tabular}


Mass Spectrometcric Studies of Sulfur Compounds :

It is generally recognized that the processes associated with doubly charged ion fragmentation may differ appreciably from those associated with singly charged ions from the same compound. Also, as is usually the case, the amount of doubly charged ions in alkyl substituted molecules decreases as the chain lengthens. In this case, the doubly charged ions are observed in greater quantity in lower molecular weight compounds and intensities are down markedly by the time $\mathrm{nC}_{6}$ is reached. This is anticipated because of the extra number of oscillators able to "soak" up excess energy. There are no metastable peaks observed to support these processes, but the interconnection of the doubly charged ion given seems reasonable. In a $15 \mathrm{eV}$ (nominal) spectrum, all of the doubly charged ions disappear. With them, peaks disappear that occur at even mass numbers but are nevertheless due, at least in part, to doubly charged ions. The $m / z 64$ and 63 peaks suffer this fate, proving that they arise from the $m / z 128$ and 126 species.

\section{Additional high resolution data}

While medium resolution provides some indication of the detailed mechanisms involved, particularly since in this case the sulfur-hydrogen doublets are often resolved, the verification of many ions must be left to the high resolution instrument. Table 4 contains data for selected mass fragments obtained on the CEC-110. Most of these ions were observed on all of the high resolution data taken and do confirm the makeup of the ions indicated. The $m / z 114$ and 113 ions were from the alpha-n-octyl compound and demonstrate that the alkyl
Table 4. High resolution data for selected mass fragments.

\begin{tabular}{lccl}
\hline$m / z$ & Experimental & Calculated & $\begin{array}{l}\text { Empirical } \\
\text { Formula }\end{array}$ \\
\hline 115 & 115.0544 & 115.0548 & $\mathrm{C}_{9} \mathrm{H}_{7}$ \\
115 & & 115.0581 & $\mathrm{C}_{6} \mathrm{H}_{11} \mathrm{~S}$ \\
114 & 114.0450 & 114.0466 & $\mathrm{C}_{9} \mathrm{H}_{6}$ \\
(larger of doublet) & & \\
114 & & 114.1408 & $\mathrm{C}_{8} \mathrm{H}_{18}$ \\
(smaller of doublet) & & \\
113 & 113.0426 & 113.0388 & $\mathrm{C}_{9} \mathrm{H}_{5}$ \\
(larger of doublet) & & \\
113 & & 113.1330 & $\mathrm{C}_{8} \mathrm{H}_{17}$ \\
(smaller of doublet) & & \\
77 & 77.0392 & 77.0391 & $\mathrm{C}_{6} \mathrm{H}_{5}$ \\
76 & 76.0314 & 76.0313 & $\mathrm{C}_{6} \mathrm{H}_{4}$ \\
71 & 71.0865 & 71.0861 & $\mathrm{C}_{5} \mathrm{H}_{11}$ \\
69 & 69.0712 & 69.0702 & $\mathrm{C}_{5} \mathrm{H}_{9}$ \\
45 & 44.9790 & 44.9799 & $\mathrm{CHS}$ \\
\hline
\end{tabular}

ion was not being formed for that compound. Even the high resolution instrument can fail at times. it is possible that cyclohexyl compound could produce an ion at nominal $m / z 115$, comprising the R-S group. The ion would be superimposed upon the 115 peak coming from the $\mathrm{C}_{9} \mathrm{H}_{7}$ ion. The accurate mass of $\mathrm{C}_{6} \mathrm{H}_{11} \mathrm{~S}$ is 115.0581 as compared to 115.0548 for the $\mathrm{C}_{9} \mathrm{H}_{7}$ ion. This is probably beyond the resolution of the CEC-110.

\section{Summary of fragmentation pathways}

Some fragmentation pathways of the alpha and beta substituted naphthylthiaalkanes are presented in Figure 2. The data obtained from the low resolution insturument permitted a fast survey, the obtaining of major features of the spectra and allowed a purity check. The medium resolution instrument provided low ionization voltage data that aided in establishing fragmentation paths and allowed some dif- 


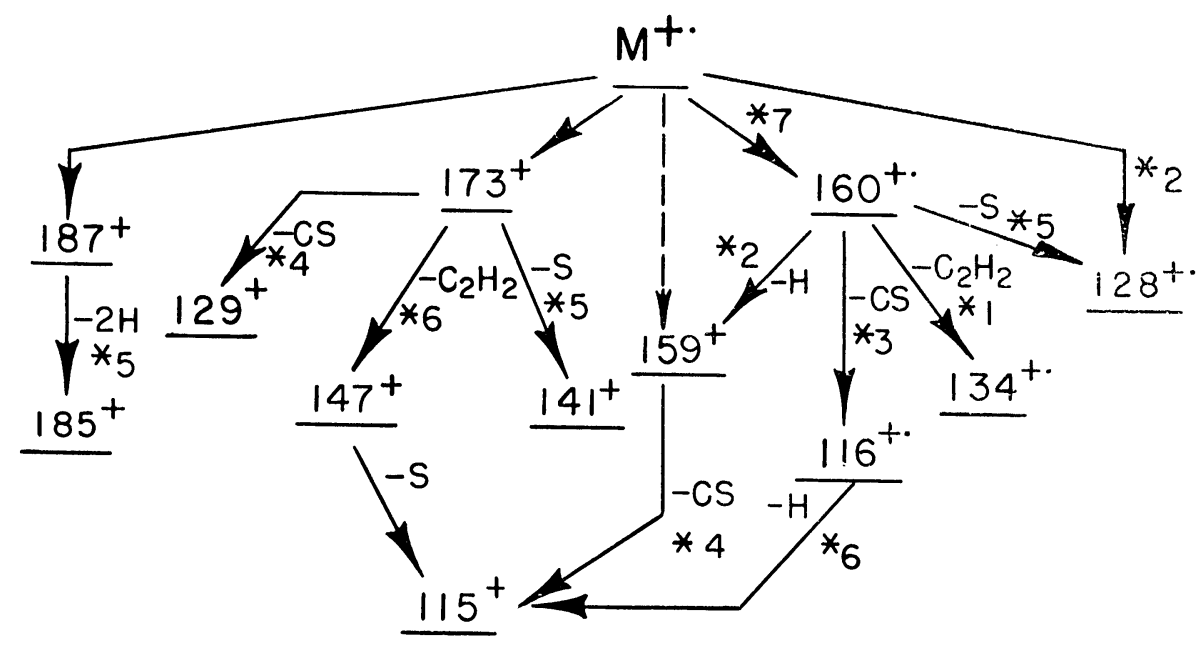

Fig. 2. Some fragmentation pathways of alpha and keta substituted Naphthylthiaalkanes.

ferentiation of ions as to sulfur or hydrocarbon in type. Both of the above instru ments allowed tentative mechanisms to be developed from the spectra obtained. Metastable ions, if observed, confirm some of the path-ways and are shown by $\star$ with the number of compounds observed in, in Figure 2. The high resolution instrument firms up mechanisms and yet may fail as was presented for the doublet at $m / z 115$ in the cyclohexyl substituted compound. When this problem occurs, labeling with natural isotopes is indicated if one wishes to delineate the mechanism. The low ionization data, if accurately taken, can assist markedly in mechanistic studies since the energetics of some of the processes may be outside of feasible ranges when compared to the observed data. Occasionally, two pathways can be suggested as in the case of the production of the $m / z 128$ ion.

\section{Acknowledgement}

At the Texas Woman's University, we should like to thank The Robert A. Welch Foundation of Houston, Texas, for support in the syntheses of these compounds, the Texas Woman's University Research Foundation for support of a portion of the work, and Misses M. Lux(spectroscopic data) and Constance Leug (syntheses) for their assistance. At Conoco Inc., we should like to thank the management for the use of analytical instruments and to Knox Moore for help in obtaining the mass spectral data.

\section{References}

1) N. G. Foster, Diana W-K. Shiu, and R. W. Higgins, Biomed. Mass Spectrom. 1, 297 (1974).

2) N. G. Foster, P. Chanrasurin and R. W. Higgins, Biomed. Mass Spectrom., (1978). Paper accepted for publication.

3) G. L. Cook, N. G. Foster, Proc. Amer. Petrol. Inst. 41, 199 (1961). 
4) E. J. Levy and W. A. Stahl, Anal. Chem., 33, 707 (1961).

5) J. E. Dooley, R. F. Kendall and D. E. Hirsch, U. S. Bur. Mines. Rep. Invest. No. 7351 (1970).

6) J. G. Pomonis, Charlotte L. Fatland and R. G. Zaylskie, J. Chem. Eng. Data 21, 380 (1976).

7) M. C. Hamming and N. G. Foster, Interpretation of Mass Spectra of Organic Compounds, Appendix I, Section D, Academic Press, New York (1972).

8) S. Meyerson, Appl. Spectry. 2, 120 (1955).

9) S. Meyerson and P. N. Rylander, J. Chem. Phys. 27, 901 (1957).

10) S. Meyerson, P. N. Rylander, E. L. Eliel and J. D. McCollum, J. Am. Chem. Soc. 81, 2606 (1959).

11) I. W. Kinney, Jr., and G. L. Cook, Anal. Chem. 24, 1391 (1952).

12) H. Budzikiewicz, C. Djerassi and D. H. Williams, Mass Spectrometry of Organic Compounds, Holden-Day, Inc., San Francisco (1967).

13) "Catalog of Mass Spectral Data," Serial Nos. 443-m-447-m. Thermodynamics Research Center Data Project, Thermodynamics Research
Center, Texas A \& M University, College Station, Texas. (loose-leaf data sheets, 1979).

14) N. G. Foster and R. W. Higgins, Paper No. 97, Fourteenth Annual Conference on Mass Spectrometry- ASTM Committee E-14, Dallas, Texas (1966). To be published.

15) J. P. Liao, N. G. Foster and R. W. Higgins, Paper No. 162, Seventeenth Annual Conference on Mass Spectrometry- ASTM Committee E14, Dallas, Texas (1969). To be published. See also Reference No. 12, Serial Nos. 21662176.

\section{Keywords}

Characteristic fragmentation

Doubly charged ions

Fragmentation scheme

High resolution data

Low ionization voltages

Low resolution data

Naphthylthiaakanes

Structural determination 